\title{
Evaluation of Long-term Creep Strength of 2.25Cr-1Mo Heat Transfer Tube in Actual Service Stress Level Range
}

\author{
Masashi NAKASHIRO, Shigemitsu KIHARA, Fumihiro KISHIMOTO') and Tohru FUJIMORI')
}

Research Institute, Ishikawajima-Harima Heavy Industries Co., Ltd., Toyosu, Koto-ku, Tokyo, 135 Japan.

Ishikawajima-Harima Heavy Industries Co., Ltd., Toyosu, Koto-ku, Tokyo, 135 Japan.

1) Boiler Plant Division

(Received on December 25, 1989; accepted in the final form on April 20, 1990)

\begin{abstract}
The creep data sheet of $2.25 \mathrm{Cr}-1$ Mo steel tube by National Research Institute for Metals (NRIM) is widely used for the residual life assessment of boiler tube. The NRIM creep data sheet contains very useful creep test results such as lower stress level than $30 \mathrm{MPa}$ and longer rupture time of over $100000 \mathrm{~h}$. Therefore, the master curve calculated from this data sheet has been noticed as a highly reliable curve. The influence of oxidation during long term creep test at low stress is very severe. As the tube's specimens of NRIM were tested on $6 \mathrm{~mm}$ diameter specimen, these data were influenced with oxidation scale more than $10 \mathrm{~mm}$ diameter specimen's creep data, and creep rupture time was become shorter.

This study was done to calculate the oxidation scale thickness and true stress variation during creep test from scale producing rate equation and to correct the rupture time with liner damage rule. As the difference of master curves between 6 and $10 \mathrm{~mm}$ diameter specimens was become very small after correcting scale effect, this correcting method was confirmed to be right.

The other's creep data sheet, ASTM and ISO, had been also investigated, and these master curves were not so much affected by oxide scale, and they had almost same creep strength level to the NRIM corrected master curve at the lower stress level.
\end{abstract}

KEY WORDS: creep; 2.25Cr-1Mo steel; Larson-Miller parameter; oxidation effect; oxide scale; life assessment.

\section{Introduction}

The 2.25Cr-1Mo steel is well used for services at elevated temperatures the world over for its hightemperature strength and good work-ability. At IHI, we are using this steel as a boiler heat transfer tube material (JIS STBA24) and have been evaluating the steel's creep properties on the basis of the creep data sheet published by the National Research Institute for Metals (NRIM), ${ }^{1)}$ which enjoys worldly fame owing to its highly reliable values obtained through well defined and uninterrupted crecp test, complete citation of chemical composition and tensile characteristic for each specimen and provision of realistic creep data, such as stresses lower than $3 \mathrm{kgf} / \mathrm{mm}^{2}$ and rupture times of over $100000 \mathrm{~h}$.

Now, we at IHI have been conducting since 1987 assessment of the remaining lifetime for old boiler plants that we have manufactured for domestic customers by sampling heat transfer tubes that have seen over $100000 \mathrm{~h}$ service out of these boilers and performing creep test on them. Fig. 1 presents two such test results for an example. It will be noted here that, irrespective of the service history, the strength degradation is apparent only on the high stress side, because the steel remains about the same as the virgin material on the low stress side.

This presents some difficulty in determining the remaining service life by the creep test on higher than applied serviced stress. The creep tests for life assessment should be conducted in the range of actual service stresses. But, the creep test on low stress side will be done at higher temperature and testing for long time. Since NRIM data for STBA24 steels had been obtained with $6 \mathrm{~mm}$ diameter specimen, these creep data had to be influenced with oxidation scalc during creep testing more than $10 \mathrm{~mm}$ diameter standard specimen. On the other hand, the results of long-term creep testing at high temperatures, such as 600 to $650^{\circ} \mathrm{C}$, will, as NRIM itself admits, have to be corrected appropriately for decrease of effective cross section by surface oxidation, as it will entail an increase in the acting stress, hence will inadvertently return an erroneous creep strength, though on the safe side; the test we contact fall rightly in this range.

In the present study, we have examined the validity of a method of correcting the creep strength to calculate the amount of oxide scale forming during creep test against the NRIM creep data sheet, and compared the correcting master curve to ISO and ASTM creep data sheet.

\section{Oxidation during Greep Testing and Its Evaluation}

\subsection{Examination of $\mathcal{N R I M}$ Creep Data Sheet}

The creep strength of $2.25 \mathrm{Gr}-1 \mathrm{Mo}$ steel due to NRIM are shown in Fig. 2 for tube (JIS STBA24) 

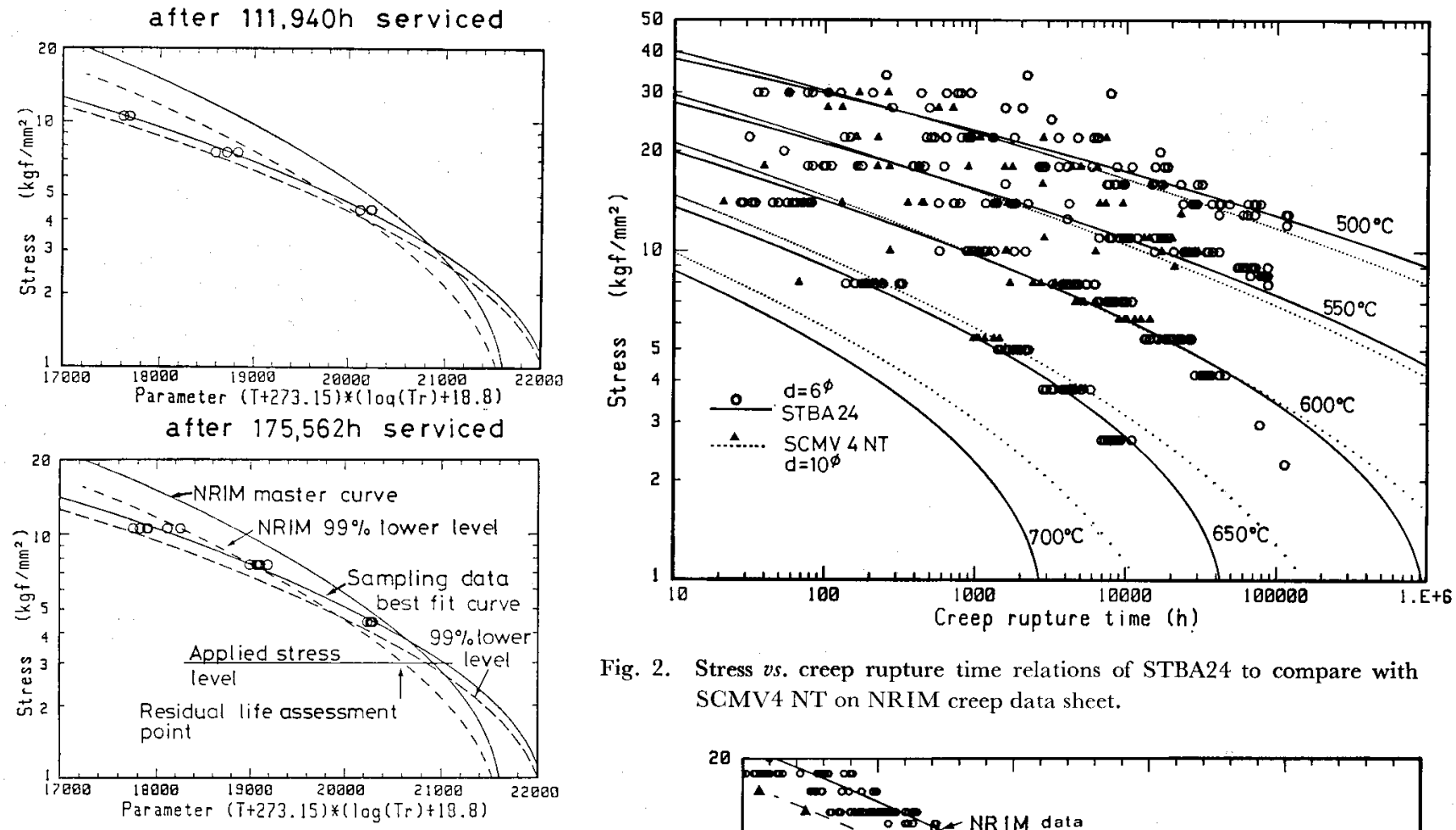

Fig. 2. Stress vs. creep rupture time relations of STBA24 to compare with SCMV4 NT on NRIM creep data sheet.

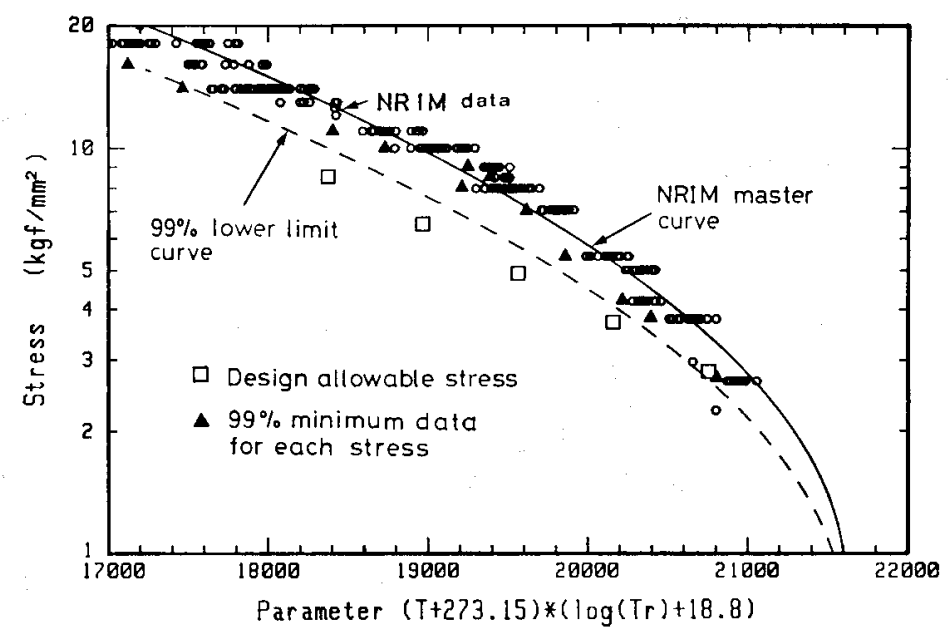

Fig. 3. Stress vs. L.M. parameter relations of STBA24 in NRIM creep data sheet and ASME design allowable stresses.

and plate (JIS SGMV4 NT). ${ }^{2,4)}$ The difference between the two steels is seen to become greater for stresses lower than $4 \mathrm{kgf} / \mathrm{mm}^{2}$, but this should be ascribed to the difference in the specimen size and geometry. ${ }^{3,5}$ )

The NRIM creep data sheet for STBA24 is reproduced in Fig. 3 together with the regression curves as a function of the Larson-Miller parameter (L.M. parameter), the $99 \%$ lower limit curve (i.e., the $99 \%$ minimum data), and the ASME design allowable stresses. We note that the $99 \%$ lower limits become to run below the design allowable stresses for stresses of $3 \mathrm{kgf} / \mathrm{mm}^{2}$ and lower. This shows that the master curve is affected by oxidation especially at low stress level and indicates erroneously short creep lifetimes.

\subsection{Effects of Oxidation Occurring during Creep Testing}

At first, the creep strength that may be expected when subjected to no oxidation was estimated. For this, loss of specimen diameter due to formation of oxide scale has been correlated to the L.M. parameter for various STBA24 materials in Fig. 4, where the solid line represents the regression curve according to NRIM, ${ }^{3)}$ which is given by;

$$
\begin{aligned}
& (T+273.15) \cdot\left(14.68+\log t_{r}\right) \\
& \quad=17030+1639 \cdot \log d+26.73 \cdot(\log d)^{2}
\end{aligned}
$$

where, $d=D_{0}-D_{t}$ : the decrease in diameter with oxide scale after $t \mathrm{~h}$ at $T^{\circ} \mathrm{G}$.

As the actual diameter loss and the regression curve agree with almost, we have used Eq. (1) to compute the effective specimen diameter after an elapsed time $t \mathrm{~h}$. $D_{t}$, as $D_{t}=D_{0}-d$, assuming that the data for diameter loss represent the scale formation habit characteristics of the $2.25 \mathrm{Cr}-1 \mathrm{Mo}$ steel, be it a virgin material or a used one.

The corrected stress at $t \mathrm{~h}$ after start of creep testing, $\sigma_{t}$, will then be

$$
\sigma_{t}=\sigma_{0} \cdot\left(D_{0} / D_{t}\right)^{2}
$$

where, $\sigma_{0}$ : the initial stress. 


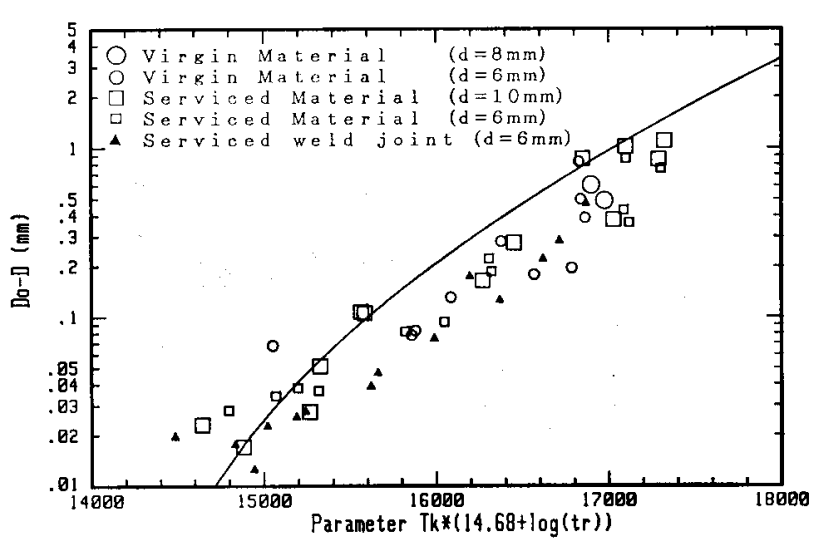

Fig. 4. Relation between the loss of specimen diameter on oxide scale and L.M. parameter for $2.25 \mathrm{Cr}-1 \mathrm{Mo}$ steel in air atmosphere test.

Assuming that the linear damage summation rule holds true for $\sigma_{t}$ as for the stresses given in terms of the L.M. parameter, we write;

$$
t_{r}(t)=t_{r} \cdot\left(t_{r} M\left(\sigma_{t}\right) / t_{r} M\left(\sigma_{0}\right)\right)
$$

where $t_{r} M(\sigma)$ are the creep rupture time given by NRIM master curve for $\sigma$ as in;

$$
\begin{aligned}
& (T+273.15) \cdot\left(18.77+\log t_{r} M(\sigma)\right) \\
& \quad=21598-334.9 \cdot \log \sigma-2318 \cdot(\log \sigma)^{2}
\end{aligned}
$$

$t_{r}$ is the creep rupture time of test result for each data.

Table 1 shows the calculating method. The creep damage factor $D_{c}$ should then be;

$$
D_{c}=\sum_{t=1}^{t_{r}} 1 / t_{r}(t)
$$

and the first order correction is;

$$
t_{r c 1}=D_{c} \cdot t_{r}
$$

These correcting methods should be applied for each data. Then, a new master curve is drawn by first correcting data. Next, first correcting equation is replaced Eq. (4), and try to calculated the second order correction with Eq. (5) for each creep data. After repeating to calculate for each creep data, the correcting master curve would bring the true master curve which is not affected by oxide scale during creep test.

It was found that four reiterations of calculation from Eqs. (2) to (6) were enough to bring the successively revised master curves into satisfactory convergence, but we have carried calculations through to the 20th order. The corrected master curves are shown in Fig. 5 with the temperature as parameter. These master curves and the individual data thus corrected are considered as giving the "true" creep strength that are free of the effects of high temperature oxidation.

The corrected data and a regression curve in their final forms are presented in Fig. 6, where the letter has been assigned with a constant $C$ of 18.77 , i.e., the same as in Eq. (4), as:

$$
\begin{aligned}
& (T+273.15) \cdot\left(18.77+\log t_{r} M(\sigma)\right) \\
& \quad=22600-1779 \cdot \log \sigma-1808 \cdot(\log \sigma)^{2}
\end{aligned}
$$

Table 1. Creep damage calculation.

\begin{tabular}{cccc}
\hline $\begin{array}{c}\text { Time } \\
(\mathrm{h})\end{array}$ & $\begin{array}{c}\text { SP diameter } \\
(\mathrm{mm})\end{array}$ & $\begin{array}{c}\text { True stress } \\
\left(\mathrm{kgf} / \mathrm{mm}^{2}\right)\end{array}$ & Damage ratio \\
\hline 1 & $D_{1}$ & $\sigma_{1}$ & $1 / t_{r(1)}$ \\
2 & $D_{2}$ & $\sigma_{2}$ & $1 / t_{r(2)}$ \\
3 & $D_{3}$ & $\sigma_{3}$ & $1 / t_{r(3)}$ \\
$\vdots$ & $\vdots$ & $\vdots$ & $\vdots$ \\
$t$ & $D_{t}$ & $\sigma_{t}$ & $1 / t_{r(t)}$ \\
$\vdots$ & $\vdots$ & $\vdots$ & $\vdots$ \\
$t_{r}$ & $D_{r}$ & $\sigma_{r}$ & $1 / t_{r\left(t_{r}\right)}$ \\
\hline
\end{tabular}

Total creep damage ratio $D_{c}=\sum_{t=1}^{t_{r}} 1 / t_{r(t)}$

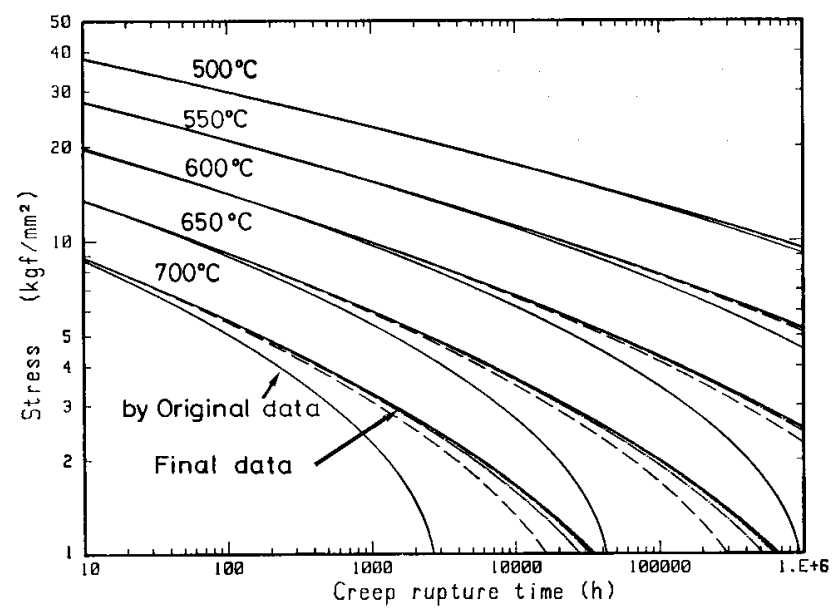

Fig. 5. Stress vs. creep rupture time relations of STBA24 to show the oxidation effect in creep test. (Calculated with Eq. (1) for NRIM data)

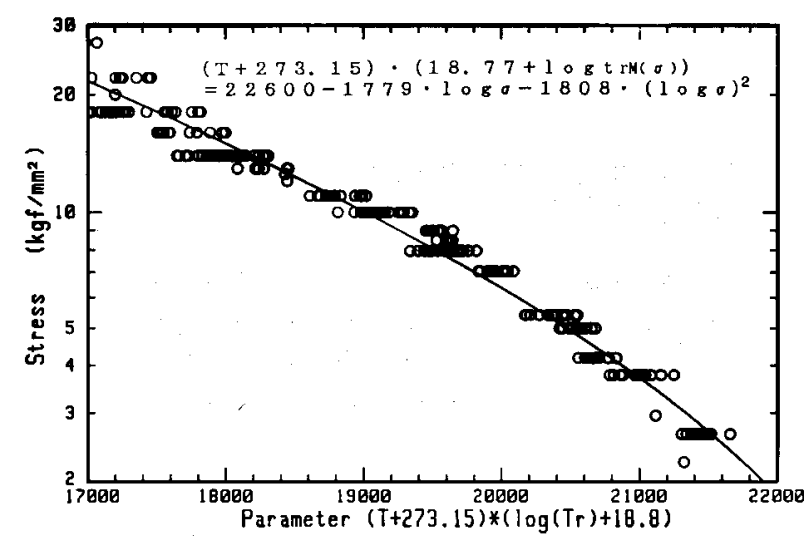

Fig. 6. Stress vs. L.M. parameter curve for STBA24, corrected for oxidation effect with NRIM scaling rate equation.

This regression curve will be called the true regression curve that has taken the effect of specimen oxidation into account.

The true data and the true regression curve have been compared with their original counterparts in terms of the life ratio, or the rupture time $t_{r}$ ratio, in Fig. 7. It will be seen that at $550^{\circ} \mathrm{C}$, the $t_{r}$ ratio remains smaller than 1.5 even for $100000 \mathrm{~h}$, indicating that the effects of oxidation may be ignored in view of dispersion of the creep data themselves. On the other hand, however, the effects are quite clear for testing times of $20000 \mathrm{~h}$ or more at $600^{\circ} \mathrm{G}$, and 


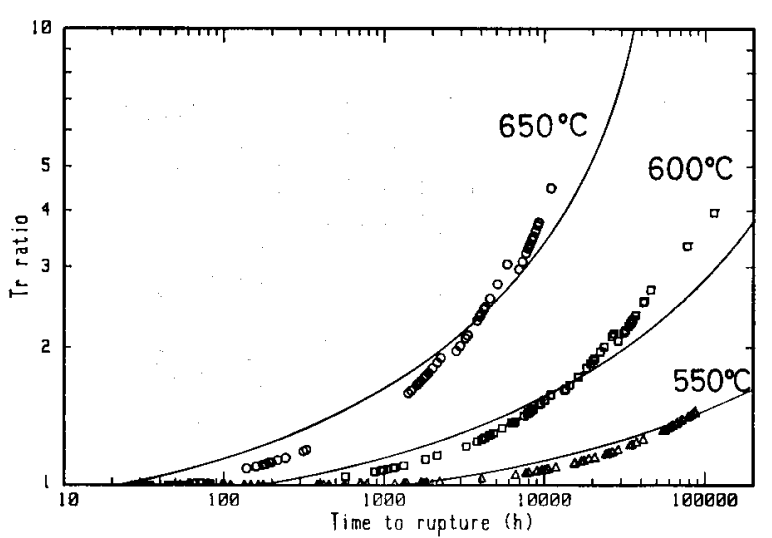

Fig. 7. Changes in the life ratio, data corrected for the effect of oxide scale to original data for NRIM STBA24 creep data sheet.

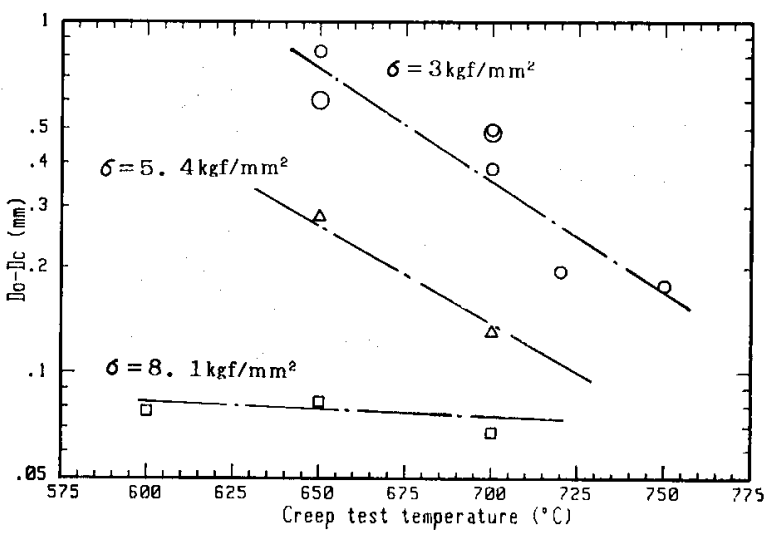

Fig. 8. Relation between the reduction of specimen diameter by oxidation and creep test temperature.

$2000 \mathrm{~h}$ or more at $650^{\circ} \mathrm{C}$. Also, the data points become deviating upwards from the curves for long testing times, indicating that the individual data can reveal more the effects of oxidation.

Relations found between the diametric oxidation loss and the temperature in iso-stress creep test are shown in Fig. 8. Here, we note that, when the applied stress is low, the oxidation loss becomes the greater, the lower the temperature, whereas that, when the stress is high, the oxidation loss remains small and about the same irrespective of the testing temperature. From this observation we conclude that it is only in the low stress, low temperature creep tests that oxidation should be considered for $2.25 \mathrm{Cr}-1 \mathrm{Mo}$ steels, the effect of oxidation being ignorantly small at high temperatures even for low stresses.

\subsection{The Case of 2.25Gr-1Mo Plate Steel (JIS SCMV4 $\mathcal{N T})$}

Effects of oxide scale formation on the $2.25 \mathrm{Cr}-1 \mathrm{Mo}$ plate steel (SCMV4 NT), which is given in Fig. 3 by means of $10 \mathrm{~mm}$ diameter specimens, were estimated the same way, and are shown in Fig. 9 in comparison with the tube steel (STBA24) and the mean creep strength deduced from the ASME design allowable stress. As may be seen in the figure, the creep strength agrees quite well between plate and tube when corrected for oxide scale. And ASME mean

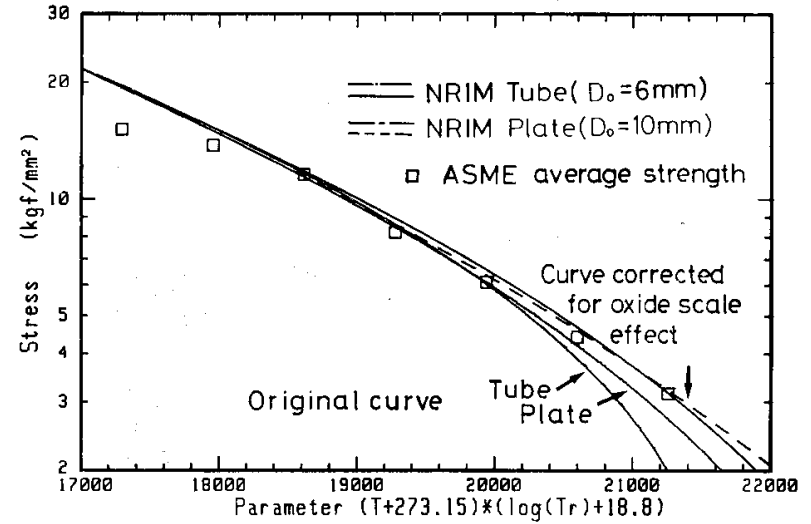

Fig. 9. Comparison of the L.M. parameter best fit curves for oxidation for experimental and corrected data for SCMV4 N'T and STBA24 with the ASME mean creep strengths,

creep strength agrees these two corrected creep master curves. This has been taken as validating the present method of correction described in the previous section.

\section{Examination of Greep Data due to ASTM and ISO}

\subsection{The ASTM Data}

The whole of the ASTM data ${ }^{6)}$ has been arranged as a function of the L.M. parameter in Fig. 10, using NRIM constant $C=18.77$ again. There are 460 data points in it, covering a temperature range of 482 to $621^{\circ} \mathrm{C}$ and a stress range of 5.7 to $50 \mathrm{kgf} / \mathrm{mm}^{2}$, but the longest creep testing time is no more than about $30000 \mathrm{~h}$.

The results of correcting for oxidation, assuming the specimen diameter to be invariably $10 \mathrm{~mm}$, are given in Fig. 11. Comparison with Fig. 10 will reveal that correction has not produced much difference from the original. This is most likely due to the total absence of data for stresses lower than $5 \mathrm{kgf} / \mathrm{mm}^{2}$, where the effect of high temperature oxidation is most felt. It is to be remembered also that the actual service stress range, which lies below the $5 \mathrm{kgf} / \mathrm{mm}^{2}$ level, is covered only by extrapolations.

\subsection{The ISO Data}

The ISO data, comprising tubes, plates, and forgings, are divided into 4 groups according to the heat treatment condition, but are arranged in 2 categories.7) Of these, those for tempering temperature below $750^{\circ} \mathrm{C}$, numbering 1077 in all, are reproduced in Fig. 12 in terms of the L.M. parameter. Because of the varied origin of individual data, the dispersion is larger here than the case of NRIM or ASTM. In particular, distribution is wider on the high stress side, where the creep strength is determined largely by the short-term strength, which is affected by the methods of manufacturing and heat treatment, and becomes narrower on the low stress side, where the specimen is in effect being heat treated while creep tested, virtually eliminating the effect of present heat 


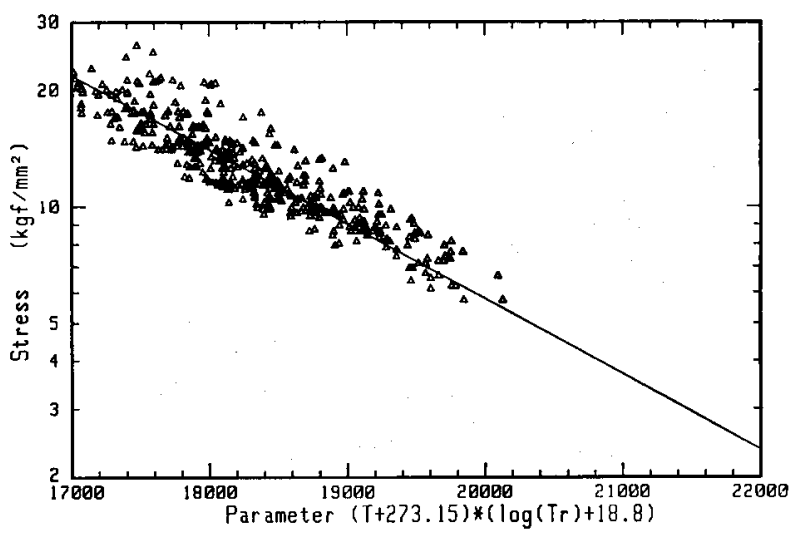

Fig. 10. Stress vs, L.M. parameter presentation of ASTM $2.25 \mathrm{Cr}-1 \mathrm{Mo}$ creep data with the best fit curve.

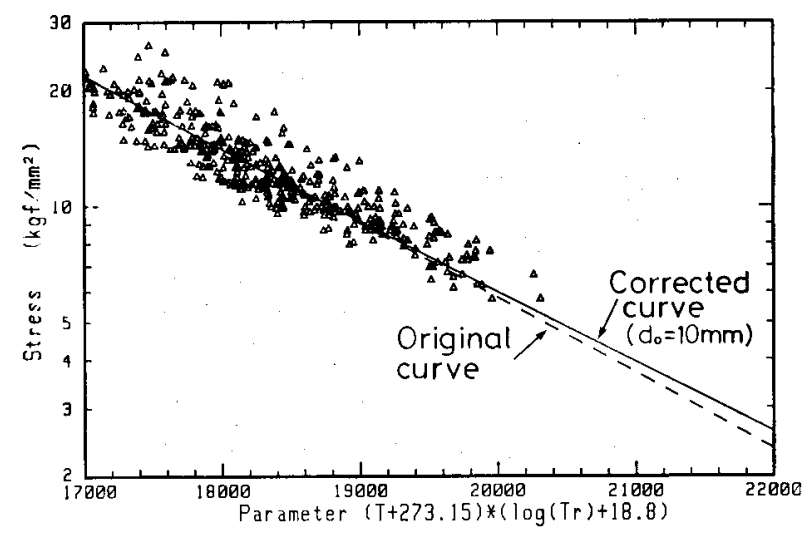

Fig. 11. Stress vs. L.M. parameter curves for ASTM $2.25 \mathrm{Cr}-1 \mathrm{Mo}$ creep data corrected for oxidation effect to compare with the original curve.

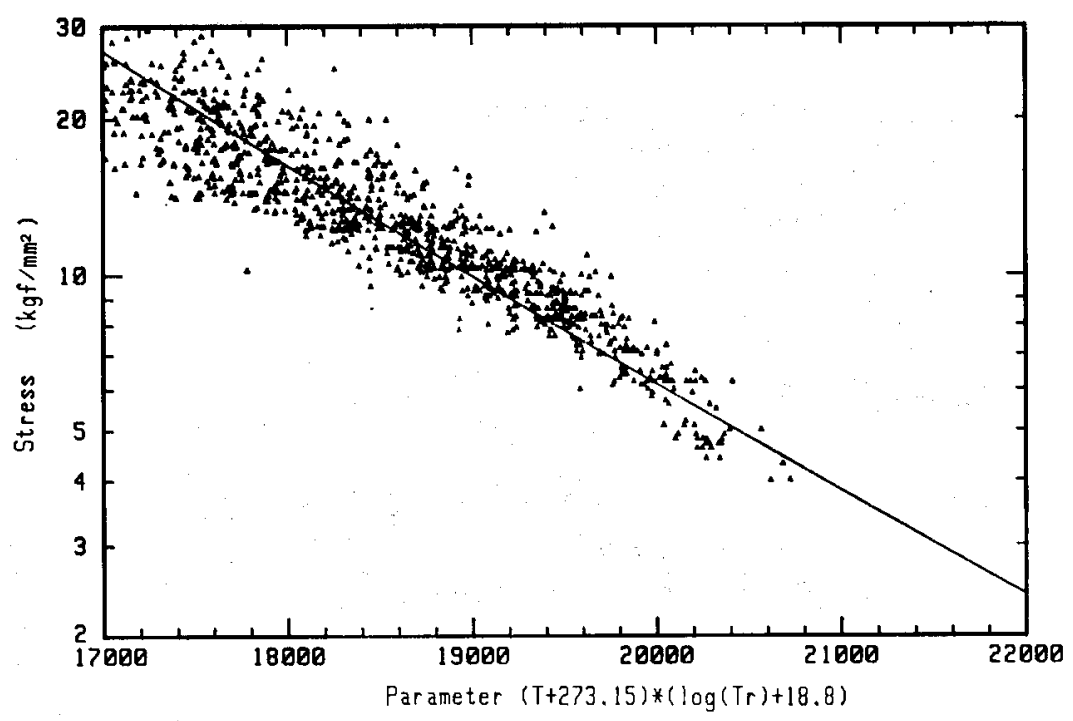

Fig. 12.

Stress $v s$. L.M. parameter presentation of ISO $2.25 \mathrm{Cr}-1 \mathrm{Mo}$ creep data with the best fit curve.

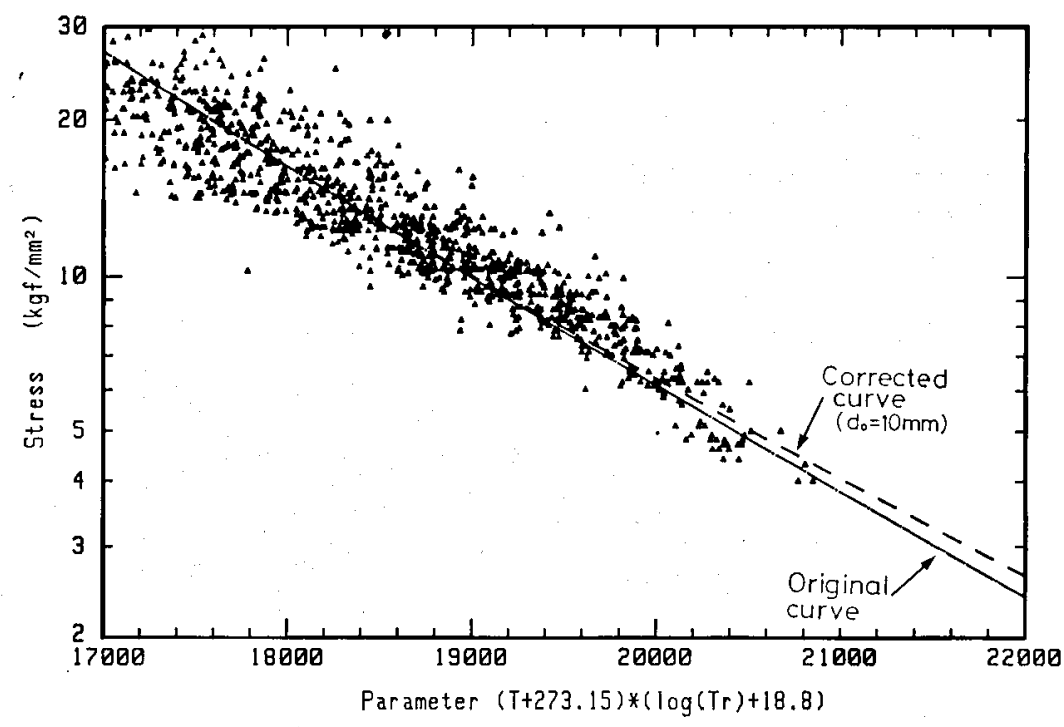

Fig. 13. $2.25 \mathrm{Cr}-1 \mathrm{Mo}$ creep data corrected for oxidation effect to compare with the original curve.

term cases, affecting little on the result of correcting

treatment.

They were corrected fo oxidation on an assumption of $10 \mathrm{~mm}$ for the specimen diameter, and shown in Fig. 13. Like the case of the ASTM data, not much difference is seen between the two regression curves, original versus corrected. This is considered due to the fact that ISO data comprise less low stress, long-term creep data compared to high stress, short- for oxidation.

\section{Comparative Examination of NRIM, ASTM and ISO Data}

Fig. 14 presents the master curves for NRIM, ASTM and ISO data, all as corrected for oxide scale 


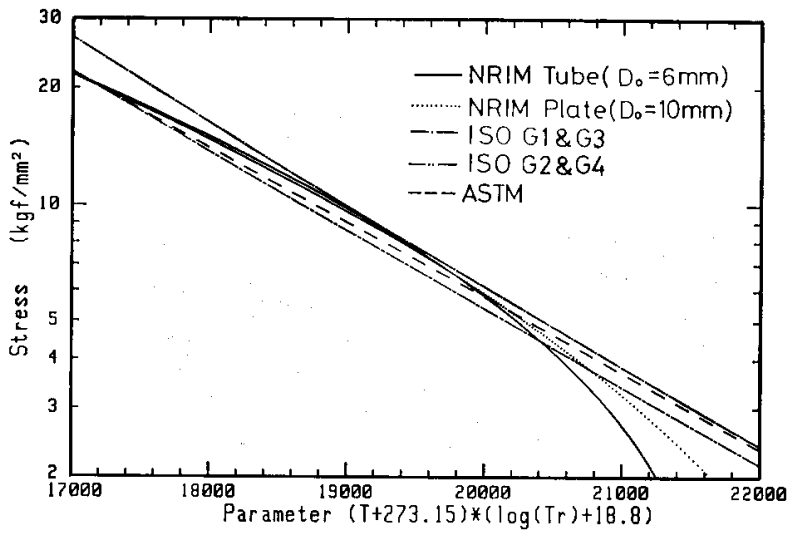

Fig. 14. Stress vs. L.M. parameter curves for $2.25 \mathrm{Cr}-$ 1 Mo steel to compare ISO, ASTM and NRIM data.

formation in the procedure described in Sec. 2.2. We note that all the data for over $5 \mathrm{kgf} / \mathrm{mm}^{2}$ can be viewed as falling between the bounds defined by the ISO data's upper and lower limits, constituting a data band. The NRIM data for under $5 \mathrm{kgf} / \mathrm{mm}^{2}$, the tube data and the plate data alike, however, are seen to fall off this data band. This is evidently a consequence of the inclusion of a great deal of low stress, long-term test results, and the smallness of the specimen in the case of tube steel $6 \mathrm{~mm}$ in diameter against $10 \mathrm{~mm}$ for the others).

Now, it will be recalled that the data due to ASTM and ISO both are those that have been obtained in conditions less liable to oxidation. Also, the testing method employed was not universally the same for all specimens. It would seem therefore that correcting these data for oxidation dose not have much of significance. The NRIM data, which are originated from one and the same testing procedure, on the other hand, should be able to bear up to precise correction.

Thus, we have taken the ASTM and the ISO data original, i.e., as uncorrected, and plotted in Fig. 15 together with the corrected NRIM data. It will be seen that the data band has now been extended as far down as to about $3 \mathrm{kgf} / \mathrm{mm}^{2}$, allowing indiscriminate use of these 3 different sets of master curves for practical purposes.

\section{Summary and Conclusions}

By developing a method of reasonably correcting the low stress, long-term creep strengths of the $2.25 \mathrm{Cr}$ 1 Mo steels for the effect of oxide scale formation, and by validating this method mainly with the data due to NRIM and also with those due to ASTM and ISO, following conclusions have been drawn.

(1) Since NRIM creep data sheet has been published on data obtained through a set of well defined and invariably followed creep testing conditions, it is quite reliable. For application to boiler heat transfer tube steel (STBA24), however, it evaluates the creep

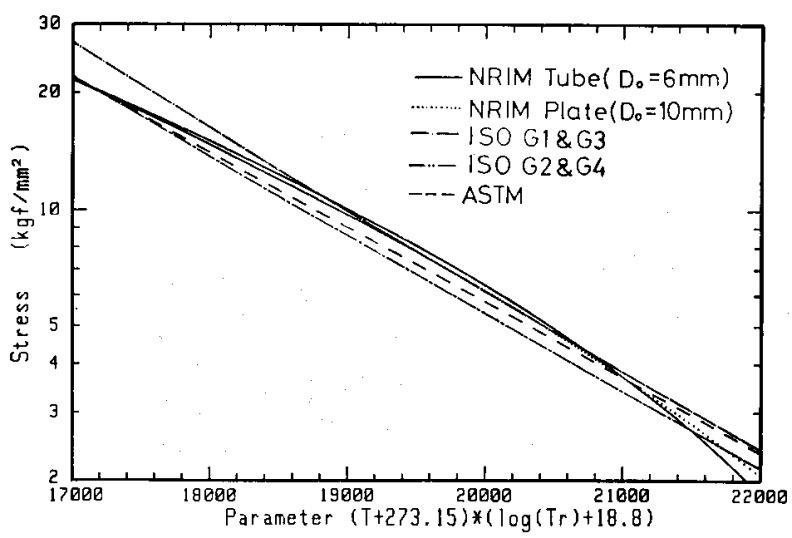

Fig. 15. Stress vs. L.M. parameter curves for $2.25 \mathrm{Cr}-$ 1 Mo steel to compare the original $1 \mathrm{SO}$ and ASTM data with the NRIM data corrected for oxidation effect.

strength on excessively safe side in the actual service stress range, unless the effect on oxidation is corrected for, because of the smallness of the specimen diameter $(6 \mathrm{~mm})$ and the inclusion of a great deal of low stress, long-term creep data.

(2) A method for calculating reasonably the true creep stress and the true rupture time has been developed on the basis of NRIM's method of estimating the oxide scale formation, and been duly validated by obtaining good agreement among the corrected NRIM data and the ASTM and ISO data when they were arranged in terms of the L.M. parameter.

(3) Conversely speaking, the original ASTM and ISO data, even though do not admit of as precise a correction for oxidation as the NRIM data because of the varied nature of testing method employed, can be taken as giving reasonable estimates of lifetime for actual boiler heat transfer tube services, provided they are assessed by the L.M. parameter method. It is to be remembered, however, that neither is satisfactory in the provision of empirical data for low stress, longterm creep.

(4) Also, the allowable design stresses due to ASME have been found reasonable.

\section{REFERENCES}

1) M. Nakashiro, K. Kihara, F. Kishimoto and T. Fujimori: CAMP-ISIJ, 2 (1989), 1939.

2) NRIM Creep Data Sheet No. 3B, Nat. Res. Inst. Met., Tokyo, (1986).

3) T. Kaneko, H. Hongho, N. Nagashima, Y. Monma and C. Tanaka: CAMP-ISIJ, 1 (1988), 900.

4) NRIM Greep Data Sheet No. 11, Nat. Res. Inst. Met., Tokyo, (1974).

5) R. Viswanathan and R. B. Dooly: The International Conference on Greep, Tokyo, Japan Soc. Mech, Fng., Tokyo, (1986), 349.

6) G. V. Smith: ASTM Data Series Publication DS 6S2, ASTM, Philadelphia, PA, (1971).

7) ISO/TG17/WG10/ETP-SG BSI, Nat. Res. Inst. Met., Tokyo, (Feb., 1971). 